\title{
THESES
}

\section{NEUROPSYCHOLOGICAL AND INTELLECTUAL STUDY OF CHILD AFTER ISCHEMIC OR HEMORRHAGIC STROKE (ABSTRACT)*. THESIS. CAMPINAS, 2008.}

\author{
INÊS ELCIONE GUIMARÃES**
}

The cerebrovascular disease (CVD) during the childhood is rare and interferes drastically in the development of child. The aim of this study is to relate the neuropsychological findings in children with ischemic or hemorrhagic CVD, to variables that interfere in the disease, for example: recurrence, etiology, the age of the installation.

Thirty-two children with prior history of ischemic or hemorrhagic stroke, of both sexes in the age group from 6 to 16 years, were subdued to an neuropsychological, intellectual, visual-motor, school performance, cerebral blood flow evaluation; among others, the sample was selected from the Group of Studies in CVD in childhood and adolescence database of the HC of UNICAMP.

Twenty-five children also the hemorrhagic with $31.25 \%$, there was no difference in relation of sex, recurrence, seizures and the age of installation of the CVA. It was noticed that $87 \%$ grew with motor sequelae and $34.3 \%$ with an intellectual reduction.

The intellectual performance was more damaged facing these situations: sickle cell disease, premature age of the installation, recurrence, evolution of convulsive crisis, two hemispheres attacked, cortical-subcortical lesion and motor sequelae. It was checked, $18.7 \%$ of the children in the experimental group could not respond to the battery of instruments, suggesting that the lesion in the cortical an subcortical areas in early age produced severe cognitive damages.

Key words: cerebrovascular disease, intelligence quotient, childhood, SPECT, recurrence.

*Estudo neuropsicológico e intelectual da criança após acidente vascular cerebral isquêmico ou hemorrágico (Resumo). Tese de Doutorado, Universidade Estadual de Campinas, UNICAMP (Área Ciências Biomédicas). Orientadora: Sylvia Maria Ciasca.

**Address: Rua Nova Iguaçu 832 / apto 302 / bloco 03 - 28890-000 Rio das Ostras RJ - Brasil (E-mail: ineselcione@yahoo.com.br).

\section{SUGAR CANE BIOPOLYMER MEMBRANE AS DURA MATER SUBSTITUTE IN WISTAR RATS (ABSTRACT)*. THESIS. RECIFE, 2008.}

\section{FREDERICO DE MELO TAVARES DE LIMA**}

Background: Duraplasty is necessary in nearly $30 \%$ of all neurological surgeries.

Objective: To determine the utilization of the sugar cane biopolymer membrane patch as a dural substitute in rats.

Method: Forty adults males Wistar rats weighing 300$440 \mathrm{~g}$ were randomly divided into two groups: a control and an experimental. All animals were anesthetized with an intraperitoneal injection of chloral hydrate in solution of $10 \%$, and placed in a prone position. Bilateral frontoparietal craniectomy was performed, and a dural defect was created. The arachnoid underlying defect was disrupted with a narrow hook. In the control animals, the defect was repaired with a disc of ePTFE. The experimental group received a membrane of sugar cane biopolymer over the cerebral cortex. No sutures in the dural patch were used in all cases. At the end of the procedure, the scalp was closed primarily in two layers. The rats were killed at 120 days. The heads were fixed by an intra-arterial injection of $10 \%$ formalin solution, followed by immersion in $10 \%$ formalin solution. After seven days of fixation, the specimens were embedded in paraffin, and the dural substitute and subjacent brain were collected en bloc. Histological sections of the biopsies were stained with hematoxilyn/eosin and evaluation was performed comparing healing and inflammatory reaction.

Results: All the animals survived to the period of 120 days to clinical observation. There were no cases of infection, cerebrospinal fluid fistulae, delayed hemorrhages, behavior disturbances, seizures and palsies. The histopathological changes of leptomeninges were semi-quantitatively scored according the inflammatory responses or foreign body reaction in the outer and inner surfaces of the membrane, the host capacity in contention the implants, and the propensity in assimilate the prosthesis. The histological findings didn't demonstrate statisti- 